\title{
Aproximación reflexiva desde el Documento de Medellín: la mirada de la filosofía de la liberación en torno a la opción preferencial por los jóvenes y los pobres"
}

\author{
Ernesto Fajardo Pascagaza* \\ Elkin Aleixi Ballesteros Guerrero ${ }^{* * *}$
}

Recepción: 17 de agosto de 2018 • Aprobación: 15 de septiembre de 2018

\section{Resumen}

El Documento de Medellín, en este artículo, es asumido desde la filosofía de la liberación y su opción preferencial por los jóvenes y los pobres. Para tal efecto, se articula a partir de cuatro variables o ejes de trabajo. En primer lugar, se presenta la contextualización de la II Conferencia General del Episcopado Latinoamericano. En segundo lugar, se hace un ejercicio reflexivo sobre la opción preferencial por los pobres. En tercer lugar, se reflexiona en torno a la misión de la educación como liberadora. Por último, se trabaja el eje sobre la filosofía de la liberación en tanto cercana a la opción preferencial por los pobres.

Palabras clave: Documento de Medellín, filosofía de la liberación, opción, jóvenes, pobres.

* Artículo de reflexión preparado para el Primer Congreso Internacional de Teología Latinoamericana y del Caribe: 50 años de Medellín: Iglesia y signos de los tiempos, desarrollado en la Universidad Santo Tomás entre el 16 y el 19 de octubre de 2018. Citar como: Fajardo Pascagaza, E. y Ballesteros Guerrero, E. A. (2019). Aproximación reflexiva desde la lectura del Documento de Medellín y la mirada de la filosofía de la liberación a la opción preferencial por los jóvenes y los pobres. Albertus Magnus, X(1), 113-130. Doi: https://doi.org/10.153322/5005413.5115.

* Universidad Santo Tomás, Bogotá, Colombia. Orcid: https://orcid.org/0000-0003-11689512. Correo electrónico: ernestofajardo@usantotomas.edu.co

*** Santo Tomás, Bogotá, Colombia. Orcid: https://orcid.org/0000-0003-0196-2677. Correo electrónico: elkinballesteros@usantotomas.edu.co 


\title{
Reflective approach from the Document of Medellin: The look of the philosophy of liberation surrounding the preferential option for young people and the poor
}

\begin{abstract}
The Medellín Document, in this text, is assumed from the Philosophy of Liberation and its preferential option for the young and the poor. For this purpose, the writing is articulated from four variables or axes of work. In the first place, the contextualization of the II General Conference of the Latin American Episcopate is presented. In a second section, a reflective exercise is done on the preferential option for the poor. In a third axis, we reflect on the mission of education as liberating. Finally, the axis is worked on The philosophy of liberation as close to the preferential option for the poor.
\end{abstract}

Keywords: Document Medellin, Philosophy of liberation, option, young people, poor.

\section{Abordagem reflexiva do Documento do Medellín: o olhar da filosofia da liberação que circula a opção preferencial para os jovens e os pobres}

\section{Resumo}

O Documento de Medellín, neste texto, é assumido a partir da Filosofia da Libertação e sua opção preferencial pelos jovens e pelos pobres. Para tanto, a escrita é articulada a partir de quatro variáveis ou eixos de trabalho. Em primeiro lugar, apresenta-se a contextualização da II Conferência Geral do Episcopado Latino-Americano. Em uma segunda seção, um exercício reflexivo é feito sobre a opção preferencial pelos pobres. Em um terceiro eixo, refletimos sobre a missão da educação como libertadora. Finalmente, o eixo é trabalhado na filosofia da libertação o mais próximo da opção preferencial pelos pobres.

Palavras-chave: Documento Medellín, Filosofia da libertação, opção, jovens, pobres. 


\section{Introducción}

El presente artículo tiene como objetivo hacer un acercamiento a la filosofía de la liberación como filosofía de la religión inculturada a partir de los presupuestos del Documento de Medellín y su pertinencia en los jóvenes y los pobres. En este sentido, se hace un análisis del lugar teológico que tiene la opción preferencial por los jóvenes y los pobres, que es la esencia germinal del documento, hito decisivo en la configuración de la identidad de una Iglesia latinoamericana, en la que ellos son la epifanía del rostro de Dios, quienes exigen una reflexión crítica sobre su praxis histórica a la luz de la Palabra. Por tanto, el perfil de la Iglesia latinoamericana ha de ser el de una Iglesia libre del poder, próxima y compañera del pueblo en su camino de liberación. En este sentido, la filosofía de la liberación, como filosofía de la religión inculturada, asume una dimensión básicamente antropológica y humanista, contribuye a la comprensión de las particularidades de la existencia del hombre latinoamericano, establece vías efectivas de liberación social y denuncia conscientemente todas las calamidades que subhumanizan y enajenan en especial a los más vulnerables y marginados de la sociedad.

Con motivo de los cincuenta años de la II Conferencia General del Episcopado Latinoamericano, realizada en la ciudad de Medellín, se abre el horizonte privilegiado para la reflexión y la contextualización de los contenidos emanados de este encuentro, los cuales buscan direccionar el devenir histórico de la Iglesia al servicio de los pobres y más vulnerables de la sociedad. Para tal efecto, se plantean cuatro ejes temáticos. En el primero, se hace un abordaje general sobre la contextualización de la conferencia. En el segundo, se reflexiona sobre la opción por los jóvenes. En el tercero, se propone un ejercicio reflexivo en torno a la educación de la liberación. Por último, en el cuarto eje, se hace referencia a la filosofía latinoamericana de la liberación en tanto lectura aproximativa a la opción preferencial por los pobres.

\section{Primer eje: contextualización de la ll Conferencia General del Episcopado Latinoamericano}

En 1968, entre agosto y septiembre, se celebra la II Conferencia General del Episcopado Latinoamericano, realizada en la ciudad de Medellín. Sin duda, este acontecimiento en el contexto de la Iglesia católica tuvo un momento especial por los aportes y las reflexiones que han resultado en II Conferencia General en 
favor de los pueblos latinoamericanos afligidos por la desigualdad, la pobreza y la discriminación. Por tanto, la II Conferencia General ha sido una manera de visualizar el futuro apostólico de la Iglesia en tierras latinoamericanas.

Cabe señalar aquí que en 2018 se cumplieron los cincuenta años de la promulgación de II Conferencia General y, por tanto, se considera pertinente hacer memoria de un antes y un después, es decir, qué concepto de Iglesia se tenía antes de ella y qué Iglesia se percibe en la actualidad. Para tal fin, es oportuno acudir a la historia y mencionar que anterior a realizarse se celebró el Concilio Vaticano II, el cual tuvo su inicio en 1962 y finalizó en 1965. El Concilio Vaticano II, de carácter ecuménico, fue convocado por el papa Juan XXIII y finalizado por el papa Pablo VI, el cual se convirtió en uno de los eventos más importantes del siglo XX, no solo por la participación de otras Iglesias cristianas, sino también porque abordó temas controversiales de la sociedad, como entrar a reflexionar sobre la dignidad de la persona y los derechos humanos proclamando la igualdad de condiciones (Parada, 1975).

Por tanto, el Concilio Vaticano II permitió proyectar una Iglesia de apertura, es decir, una Iglesia abierta al diálogo. Esa institución anterior, que parecía un poco rígida o doctrinal, hace un cambio en su forma de pensar haciendo lectura de los tiempos y tratando de caminar con las transformaciones sociales actuales para la acción pastoral de la Iglesia. Los cambios planteados por el Concilio Vaticano II no son para la fe ni para agregar nuevos dogmas, sino para explicar la fe, y hacerla más comprensible para los hombres inmersos en el contexto de una sociedad moderna.

Posterior a la finalización del Concilio Vaticano II, en 1968, se da inicio a la II Conferencia General del Episcopado Latinoamericano. Ahora bien, esta se enmarca, esencialmente, en la revisión del aspecto pastoral y, por ende, va en relación con lo propuesto en el Concilio Vaticano II, en el que se hace énfasis en los signos de los tiempos y en la renovación de una Iglesia con celo apostólico. Es importante recordar en este momento que fue Pablo VI quien viajó a Colombia para inaugurar la II Conferencia General, y como legado de su labor como pastor eclesial se tiene su encíclica Populorum progressio, en la cual denuncia que el desequilibrio entre países ricos y pobres se va agravando. También hace una fuerte crítica al neocolonialismo y manifiesta abiertamente el derecho de todos los pueblos al bienestar. Finalmente, la encíclica propone la creación de un fondo mundial para apoyar a los países en vías de desarrollo (Parada, 1975).

En el preámbulo de la encíclica, se afirma:

El desarrollo de los pueblos y muy especialmente el de aquellos que se esfuerzan por escapar del hambre, de la miseria, de las enfermedades 
endémicas, de la ignorancia; que buscan una más amplia participación en los frutos de la civilización, una valoración más activa de sus cualidades humanas; que se orientan con decisión hacia el pleno desarrollo, es observado por la Iglesia con atención. Apenas terminado el segundo Concilio Vaticano II, una renovada toma de conciencia de las exigencias del mensaje evangélico obliga a la Iglesia a ponerse al servicio de los hombres para ayudarles a captar todas las dimensiones de este grave problema y convencerles de la urgencia de una acción solidaria en este cambio decisivo de la historia de la humanidad. (Pablo VI, 1967, n. 1)

Ciertamente, lo anterior deja percibir que la intención de la encíclica está establecida sobre la necesidad de promover el desarrollo de los pueblos. Para tal pretensión, hace un llamado a la Iglesia, que tiene como obligación pastoral ponerse al servicio de los hombres para ayudar a transformar la realidad desde acciones concretas.

Ahora bien, de acuerdo con lo acontecido en el Consejo Episcopal Latinoamericano (Celam), es necesario mencionar que durante este encuentro se hace un claro discernimiento de la situación de pobreza y subdesarrollo en que viven gran parte los pueblos latinos. Sin embargo, este no es un problema solo en Latinoamérica, sino que, por el contrario, es uno que aqueja en gran medida a muchas naciones, donde la desigualdad social es el común denominador. Por esta razón, lo dialogado en Medellín ha causado gran resonancia en Europa y otros continentes, que ven el compromiso de una Iglesia fuerte a pesar de sus limitaciones (Celam, 1989).

\section{Segundo eje: opción por los jóvenes}

En este primer apartado, es importante mencionar que es la primera vez que se dedica un documento a los jóvenes, y esto podría interpretarse como un llamado de atención ante la importancia de la inclusión de estos en el campo de la Iglesia y la sociedad. Por ende, puede afirmarse que los jóvenes en esta ocasión son descritos de manera más sutil para hacer fructificar todo el potencial que tienen, y que podrán aportar a la labor pastoral de la Iglesia, para así lograr sujetos que sean capaces de salir al encuentro y tomar la opción preferencial por los pobres.

Durante la II Conferencia General del Episcopado Latinoamericano, los obispos partícipes hacen un análisis de las peculiaridades de la juventud actual, y reconocen que 
la juventud se presenta como un nuevo cuerpo social portador de sus propias ideas y valores, que vive a la vez una época de crisis y cambios que son causa de conflictos, lo que exige un sincero esfuerzo de comprensión y diálogo. (Parada, 1975, p. 56)

En este sentido, los jóvenes son elemento esencial en la construcción de nuevas alternativas eclesiales, ya que sus ideas y valores contribuyen a consolidar proyectos que guíen una sociedad fracturada por los distintos problemas ecológicos, sociales y económicos, entre otros, pero también es importante resaltar cómo se percibe en los jóvenes, que son sujetos que viven crisis propias de la época, y por eso se hace necesario un diálogo que emerja desde la comprensión y la transformación de entornos.

Asimismo, se menciona que la juventud es particularmente sensible a los problemas sociales y reclama los cambios profundos y rápidos que garanticen una sociedad más justa, exigencias que en ocasiones son expresadas mediante la violencia, como forma de reclamar por aquello que no es justo (Parada, 1975). Por tanto, debe generarse un espacio donde los jóvenes sean escuchados, y tenidos en cuenta con sus propuestas a la hora de aportar en la construcción de una sociedad más justa que involucre la opción preferencial por los pobres y excluidos.

Dentro de este análisis generado en la II Conferencia General del Episcopado Latinoamericano, se destaca que los jóvenes tienden a reunirse en grupos o comunidades que cada día se expanden más y más. Lo que cuestiona es que estos grupos están emergiendo con ideologías en las que hay un rechazo a las instituciones, especialmente con la Iglesia como institución. En este sentido, la Iglesia debe abrirse a nuevos retos en los que se propongan ideas que congreguen a los jóvenes, con iniciativas para hacer de esa institución llamada Iglesia un espacio de creatividad e innovación. Por lo anterior, es oportuno referenciar el Concilio Vaticano II en el que se propone una Iglesia abierta al diálogo con las culturas y dispuesta a crecer junto con el pueblo y los hombres que las conforman.

No obstante, se debe tener en cuenta que para que tanto los jóvenes como la Iglesia tiendan a una apertura desempeña un papel fundamental la familia, ya que "la familia es la primera escuela de las virtudes sociales que necesitan todas las demás sociedades [...] Encuentran en la familia los hijos la primera experiencia de una sana sociedad humana [...] y se introducen poco a poco en la sociedad civil y en la Iglesia" (Pablo VI, 1965, n. 3). Por tanto, el núcleo familiar es y será la herramienta esencial de toda sociedad, pues en ella se fundamentan todos los principios éticos que el ser humano debe poseer, además, "la familia es escuela del más rico humanismo" (n. 52). En este sentido, la familia se convertirá 
en el lugar donde se enseña desde el ejemplo a hacer cada día más humano. "La familia, en la que coinciden diversas generaciones y se ayudan mutuamente para adquirir una sabiduría más completa, y para saber armonizar los derechos de las personas con las demás exigencias de la vida social, constituye el fundamento de la sociedad" (n. 52). Desde el seno de una familia bien consolidada, es decir, fundamentada en valores éticos y morales, el joven considerará su entorno vital, y se convertirá en agente generador de cambios, en una persona consciente de su realidad y la realidad que vive la humanidad y, por consiguiente, valorará de manera responsable el cumplimiento de sus obligaciones irrenunciables fruto de su espíritu juvenil en relación con quienes son excluidos y marginados.

\section{Tercer eje: educación liberadora}

En la actualidad, la comprensión sobre la educación es amplia, y en este orden, se acude como referencia a la Ley 115/1994, de 8 de febrero, por la cual se expide la ley general de educación para afirmar que "la educación es un proceso de formación permanente, personal, cultural y social que se fundamenta en una concepción integral de la persona humana, de su dignidad, de sus derechos y de sus deberes". Se muestra, de este modo, un gran interés por formar personas integrales, con capacidad de desenvolverse eficientemente en la sociedad, desarrollando capacidades de dominio cultural y, sobre todo, con valores propios a partir de una formación sensible y humana.

Lo anterior, de una u otra manera, está en armonía con los aportes que ofrece la II Conferencia General del Episcopado Latinoamericano cuando se refiere a la educación en tanto un proceso fundamental y esencial en la formación integral de toda persona. Sin embargo, un valor agregado en el contexto de la II Conferencia General es que la educación es efectivamente el medio clave para liberar a los pueblos de toda servidumbre y promover personas capaces de ser líderes, para que emprendan nuevos caminos, teniendo en cuenta que cada hombre es directamente el responsable y el artífice de su éxito o fracaso.

Así es que una educación liberadora debe ser aquella que pueda dar respuestas a las necesidades culturales, es decir, una educación en contexto, en el que emergen soluciones a los distintos problemas actuales. En este sentido, hoy debe hacerse una reflexión sobre el panorama de una educación que proponga liberación de estructuras buscando dignificar a la persona, a partir de una visión de educación conforme al desarrollo integral de todos los pueblos y naciones (Parada, 1975). 
Por consiguiente, la educación liberadora debe tener como objetivo primordial convertir al educando en sujeto de su propio desarrollo; en ella, las oportunidades deben estar dadas para todos en igualdad de condiciones sin acudir a las jerarquizaciones, sino proponer una educación que esté al servicio de la comunidad. En otras palabras, una educación que esté mediada a través de la responsabilidad social. Personas transformadoras de su entorno y realidad social. El sentido humanista y cristiano de la educación debe tener como fin dignificar al ser humano, es decir, que la persona se sienta querida, reconocida y amada. Comprendida así, "la educación en todos sus niveles debe llegar a ser creadora, pues ha de anticipar el nuevo tipo de sociedad que buscamos en América Latina" (Celam, 1989, p. 49).

Finalmente, en las conclusiones dadas en el Celam, específicamente en el apartado dedicado a la juventud, se resalta que debe educarse desde el sentido humanista cristiano, lo que permitirá un diálogo abierto, para enriquecerse con los valores que la juventud (Celam, 1989). Lo anterior lo afirma el mensaje dado en el Concilio Vaticano II cuando señala que los jóvenes podrán ser el ejemplo de las enseñanzas de sus padres y maestros, y formar la sociedad del mañana, una sociedad comprometida responsablemente con el devenir histórico de los pueblos. Sin duda, el mensaje dado en los dos documentos eclesiales deja ver una luz de esperanza fuerte en los jóvenes a partir de una acción transformadora y una Iglesia renovada con creatividad e innovación desde los jóvenes.

Si bien en la II Conferencia General del Episcopado Latinoamericano se abordó la opción por los jóvenes y una educación liberadora, después de cincuenta años de este magnífico encuentro, debe analizarse qué tanto se ha logrado avanzar en aquellas propuestas dadas. Pareciera que se viene cultivando algunos elementos importantes, como la Jornada Mundial de la Juventud (JMJ), y también el sentido del humanismo en las universidades, pero igualmente debe seguirse trabajando en la construcción de una sociedad más justa en la que el valor de la equidad sea algo más experiencial entre las distintas culturas, y con tal propósito, una oportunidad valiosa para seguir creciendo como sociedad más humana para lo cual debe seguirse pensando en una filosofía y una teología de la acción, es decir, un quehacer transformador, y no, por el contrario, en teorías que, en ocasiones, poco pueden trasladarse a la realidad: “La teología no debe limitarse a ser frío y objetivo intellectus fidei [...] ha de entenderse, más bien, como intellectus amoris et misericodiae que se hace cargo del sufrimiento de las víctimas desde la compasión, toma partido por los derechos de los seres humanos y los pueblos empobrecidos" (Tamayo-Acosta, 2004, p. 25). 
Cuando se reflexiona en torno a la teología de la liberación, se podría señalar que la categoría articuladora de la acción teológica es el principio de la misericordia, de ahí que se afirme que se entiende por ese principio como el origen de un proceso (Tamayo-Acosta, 2004), y por tanto, la misericordia es el principio fundamental de la acción de Dios en la historia, que opta por la liberación de aquel que sufre; este no será un sentimiento anímico que está dado por obras piadosas y caritativas, sino que es un elemento vital que impregna en el ser humano la esperanza, la compasión y el amor. Para Vidales (1978):

La praxis concreta por la liberación de los oprimidos es el lugar donde somos encontrados por el señor en la medida que nos adherimos a su persona en la persona de todos los explotados; por tanto no solo en aquellos que componen las clases sociales que están llamados a ser la vanguardia del proceso revolucionario, sino también en los sectores que más padecen la sobre-explotación del sistema dominante. (p. 176)

Hace cincuenta años se celebró la II Conferencia General del Episcopado Latinoamericano, en la que importantes líderes del catolicismo analizaron y reflexionaron sobre la realidad de los pueblos latinos. Allí, la Iglesia lee e interpreta los signos de los tiempos, para que se adecúe a las exigencias de la época. Un aporte importante está dado desde lo sucedido en el Concilio Vaticano II, del cual emergen varias propuestas que serán pensadas para el contexto latinoamericano. También conviene señalar que, al pensar en el hombre y en la sociedad latina, aparece la filosofía latinoamericana como una forma de examinar, preguntar e indagar lo que sucede en la realidad de estos pueblos. Esta propuesta filosófica y teológica surge como una manera de afirmar con propiedad que la pobreza y la exclusión también se constituyen en una forma de pecado, y se hace un llamado para luchar, para liberarse de tales males. Ahora bien, es claro que la Conferencia de Medellín es la oportunidad para que la sociedad se comprometa con los pobres y afligidos que buscan esa compasión que menciona precisamente el papa Pablo VI en su encíclica Populorum progressio, de modo que es el sentido de una acción solidaria en el cambio decisivo de la historia de la humanidad.

Es fundamental la participación de los jóvenes como agentes transformadores de la realidad, y también el significativo papel que desempeñan las universidades en una educación basada en el humanismo cristiano que pretenda formar personas comprometidas con la sociedad, capaces de enfrentar los retos y desafíos del siglo actual, a partir de la opción por los pobres y afligidos aunándose al sentir de aquel que opta por la liberación de quienes sufren. 


\section{Cuarto eje: la filosofía de la liberación cercana a la opción preferencial por los pobres}

La filosofía de la liberación inicia en la realidad concreta de los pueblos latinoamericanos en su experiencia práxica histórico-social humana integral, en tanto se acerca a las víctimas de los fenómenos de injusticia e inhumanidad.

Este movimiento filosófico latinoamericano comienza a tomar fuerza a fines de la década de 1970. Su génesis responde a los proyectos emancipatorios de la humanidad y las reflexiones filosóficas de los últimos tiempos. De alguna manera, el marxismo ha sido motivo de inspiración en el compromiso con los oprimidos que desean una genuina liberación humana, ante un capitalismo dominante y opresor. La filosofía latinoamericana de la liberación no constituye propiamente una escuela filosófica, sino un movimiento intelectual que, no obstante la heterogeneidad que subsiste en su seno y que se puedan definir incluso corrientes dentro de ella, existen determinados elementos concluyentes. Es innegable que todos aspiran a la liberación del hombre latinoamericano, del hombre mayor, del niño y del joven, aun cuando muchas de las propuestas para lograrla no sean mucho menos abstractas que las que critican en otras filosofías, sin embargo, coinciden en la necesidad de poner la filosofía en función de expresar las necesidades de la realidad latinoamericana para transformarla. En tal sentido, es una filosofía de denuncia y de crítica a las alienantes condiciones que el colonialismo ha traído para el hombre latinoamericano.

Hay diferentes vías que se proponen para encontrar esta liberación. En consecuencia, está la línea que considera la liberación a partir de una óptica culturológica, del ethos cultural, con la intención de rescatar los valores autóctonos enajenados por la imposición de una cultura dominadora. Desde este enfoque se comprende que la cultura debe buscarse en los fundamentos mítico-éticos y religiosos, a partir de una medición simbólica que descansa en un espontaneísmo correlativo a una postura irracionalista y fideísta. En este sentido, según Galindo (1990), Juan Carlos Scannone desarrolla como proyecto de liberación una filosofía y una teología que se inculturen, a través de la vía del desarrollo de una cultura popular para liberar a los pobres y sencillos de América. En su lenguaje está muy presente el término opción preferencial para los pobres, al considerar que en América fueron ellos los que mejor supieron resistir a las culturas impuestas y preservar la cultura popular latinoamericana, con lo cual formaron lo medular del proceso de liberación social y cultural. 
Otra línea considera que las posibilidades de liberación están dadas a partir del dominio de la racionalidad como vía efectiva para desalienar al hombre latinoamericano, que supera la plena humanidad mediante el consenso basado en la razón como aceptación de un modelo autónomo de humanidad. En este sentido, para Salazar (1969) la filosofía de la liberación tiene su proyecto final en la denuncia a partir de las situaciones de subdesarrollo, de dependencia y de dominación que afecta al hombre latinoamericano, al hombre concreto de carne y hueso (Miró, 1974). La liberación del hombre resultará real cuando estos vivan de acuerdo con la razón en la media en que la sociedad elimine la arbitrariedad de lo irracional, del dominio de unos sobre los otros, de la opresión para alcanzar la plena humanización como racionalidad de una vida social más justa, más humana, más consciente de la necesidad de eliminar la arbitrariedad, es decir, vivir conforme a la razón, con más humanidad.

Igualmente, hay una línea que se dirige hacia la democracia efectiva que permite libertades políticas, culturales y económicas como condición de libertad plena del hombre. En este orden, hay una nueva línea de la liberación que se acerca a las propuestas marxistas en las que la solución a la libertad y la independencia del continente solo es posible a través de una revolución nacional liberadora de trascendentes dimensiones sociales que supere las enajenantes relaciones capitalistas y se oriente hacia el socialismo. Se trata de una filosofía de la liberación comprometida con el otro, es decir, con el pueblo latinoamericano (Dussel, 1980).

Esta filosofía de la liberación, sin atentar contra la esencia universal de la filosofía, exige una reflexión filosófica desde y para Latinoamérica, sin que sus categorías y enunciados se presupongan exclusivamente válidos para esta contextualidad, sino como proyecciones universales. Lo cierto es que esta corriente de pensamiento ha trascendido más por sus grados de autenticidad que por su originalidad.

La filosofía latinoamericana de la liberación tiene una dimensión básicamente antropológica y humanista. Aun cuando en los momentos ontológicos, epistemológicos y axiológicos afloran con necesaria frecuencia en los discursos de sus representantes, esto solo se hace en función de contribuir a una mejor comprensión de las particularidades de la esencia humana expresada de modo concreto a través de las condiciones de existencia del hombre latinoamericano contemporáneo, para de ese modo establecer las vías efectivas de liberación social. La filosofía de la liberación ha desempeñado un papel concientizador al denunciar todas las calamidades que subhumanizan al hombre latinoamericano. El filósofo en tanto persona, y en el ejercicio de su filosofar, responde a la interpelación 
ético-histórica que proviene de los pobres, del marginado y del oprimido en su alteridad irreductible y su liberación humana integral y justa (Marion, 2006).

Esta filosofía ha criticado de manera vehemente las diversas formas de enajenación que se dan en la sociedad burguesa, en especial la explotación de obreros, campesinos e indígenas; la desinformación y la formación de patrones culturales extraños impuestos a través de los medios de comunicación; la miseria de amplios sectores; la drogadicción; la prostitución; la mendicidad; la corrupción administrativa; la indiferencia de sectores gobernantes; la inseguridad social; entre otras circunstancias problemáticas de la sociedad.

Los latinoamericanos asumen culturas que no son propias, pero que por la fuerza impositiva han prevalecido, por lo que han perdido el ser sujetos de su propia cultura, se han llenado de hedor ante la pulcritud del hombre occidental (Kusch, 1986) y han reclamado un sujeto cultural desde su historia popular (Kusch, 1978), en la búsqueda de una autenticidad en su filosofar (Kusch, 1976), en que el pueblo es el sujeto de la sabiduría popular. Por tanto, la sabiduría popular tiene un carácter religioso, y aunque es propia del pueblo, está representada en los pobres y sencillos, en los que se logrará ese nuevo proyecto liberador $(\mathrm{Cu}-$ llen, 1986). En este sentido, la categoría pueblo es asumida ontológicamente de modo que es el mero estar con sentido ético de justicia.

El pueblo es el creador del ethos cultural que tiene en cuenta lo ético, es decir, los valores morales que tiene una comunidad (Scannone, 1985), de tal forma que cada pueblo se manifiesta en símbolos, posee sus propias leyendas, sus propios mitos y tiene su memoria histórica. Para el escenario latinoamericano, no es claro el panorama que se brinda para la filosofía debido a la implicación e incidencia de la Primera y Segunda Guerra Mundial, así como a las consecuentes miradas frente a los procesos de deshumanización que generaron los campos de concentración de Auschwitz, que dio lugar a una desazón crítica y latente en el mundo filosófico. Se suscitan preguntas filosóficas por Dios, como ¿dónde estaba Dios mientras el Holocausto, mientras la injusticia?

Estos y otros cuestionamientos llevan a un nuevo pensamiento del estar en estrecha relación con lo trágico de las víctimas y lo insondable del misterio del mal y del misterio de Dios que es amor, lo que lleva a replantear el misterio de Dios desde las víctimas (Scannone, 2005). Dios es amor, libre y gratuito que pasa por la seriedad, el dolor, la paciencia y el trabajo de lo negativo. En este sentido, para Girard (1965), la redención del mal no es vindicativa, sino que se da en el amor sacrificial hasta el extremo de Dios mismo en Jesús, porque la victoria sobre el mal es realmente posible. Por eso, cuanto más mal, tanto más bien. 
Adorno (2005) expresa de manera categórica el sentir frente al fracaso de la razón y, por consiguiente, del papel que tiene como teoría simple la filosofía:

La filosofía está obligada a criticarse a sí misma sin contemplaciones [...] Las cápsulas conceptuales que, según costumbre filosófica, debían poder acoger al todo, a la vista de la sociedad desmesuradamente expandida y de los progresos del conocimiento positivo de la naturaleza, parecen reliquias de la primitiva economía mercantil en medio del tardocapitalismo industrial. (pp. 15-16)

Hay conciencia de tocar el límite en el que la praxis y el pensar de totalidad están en crisis; es la crisis de la subjetividad, del ego cogito, del "yo puedo, yo conquisto", de la autoconciencia progresista y de la ciencia como paradigma de racionalidad y panacea universal. Por tanto, el sufrimiento de los inocentes constituye un límite para toda absolutización de la razón misma (Scannone, 2005).

Por otra parte, el mundo de la teología no queda a salvo de estas lecturas críticas dado que han de perder sentido todo tipo de discusiones religiosas que se quedan en especulaciones tridentinas frente a la inminencia trágica de Auschwitz $y$, por ende, hablar de Dios no tiene sentido. Sin embargo, en el contexto latinoamericano, hay una nueva lectura para la teología y es la realidad de marginación y pobreza que viven sus pueblos, y como respuesta concreta ante estas circunstancias, surge la teología de la liberación, para hablar y responder a las preguntas fundamentales sobre la existencia de un Dios con nosotros, un Dios cercano al pobre, al latinoamericano de a pie.

El pobre es el que conserva como estructurante de su vida y convivencia la cultura propia de su pueblo (Documento de Puebla, n. 414), de su memoria histórica, aunados en un proyecto de justicia y paz que transparenta la cultura común de su pueblo (Boasso, 1974). Como respuesta a estos nuevos escenarios que se han de abordar desde la reflexión filosófica y teológica, Scannone (2005) aclara el significado de los cuestionamientos suscitados:

Las preguntas apuntan a recomprender la cuestión (religiosa, teológica, filosófica) de Dios desde la pasión injusta de las víctimas históricas. No tanto porque el Holocausto (y los holocaustos) pongan en duda - como en una nueva teodicea - la bondad, el poder o la misma existencia de Dios, sino porque muestran la crisis de un cierto tipo de racionalidad y exigen una racionalidad nueva, desde la cual también será posible recomprender la pregunta (religiosa, teológica, en nuestro caso: filosófica) por Dios. (p. 103) 
En este sentido, tanto la filosofía de la liberación como la teología de la liberación van a ser los baluartes para desarrollar una filosofía en y desde América Latina a partir de las condiciones históricas y políticas, y la necesidad de emanciparse de las recurrentes herencias opresoras de la Conquista, de la monarquía española, de los vejámenes de la Iglesia católica, de la dominación colonial así como de la dominación británica y americana. Ante esta realidad, Scannone (2005) aclara que,

en América Latina, además de esa apertura filosófica al otro sufriente injustamente - que nos asemeja al nuevo pensar europeo de raíces judías, y corresponde a nuestra herencia cristiana-, se dio un nuevo fenómeno filosófico: el descubrimiento del pensar sapiencial indoamericano (y afroamericano) que forma parte del "mestizaje cultural" dado al origen de nuestra sabiduría popular [...] Se trata, por tanto, de otro "nuevo pensamiento" - de raigambre amerindia y mestiza, aunque interpretada en diálogo con la filosofía occidental-, cuyos aportes habrá que considerar al replantear la cuestión de Dios desde las víctimas, conjugándolos con lo nuevo y lo viejo de la tradición venida de Europa y reinterpretada en nuestra América. (p. 108)

A América Latina le corresponde vivir una praxis situacional e históricamente concreta a partir de la realidad de sufrimiento que padecen las víctimas y la necesidad de liberación y reivindicación de los más necesitados. Esta praxis implica abrirse al dinamismo de la autotrascendencia que es característica esencial del hombre y su relación con los otros como conversión afectiva que es. Según Scannone (2005),

esa respuesta dada no solo con la decisión ética (Adorno), sino también con el afecto del corazón. En América Latina - tanto para la filosofía como para la teología de la liberación - no se trató solo del otro individual, sino social, sobre todo, de las víctimas de la opresión y la exclusión, que mueven el corazón (de personas y grupos sociales) a la misericordia y a la praxis de la justicia. (p. 135)

Ahora bien, se trata de una respuesta desde la liberación a partir del lenguaje teológico como teología filosófica. Al respecto, Solari (2005) afirma que

Scannone emplea la expresión "filosofía de la religión" tal como lo hace W. Weischedel, es decir, como "teología filosófica o lógos (filosófico) acerca del theós". Este theós es el Dios vivo del que habla Pascal, el misterio sagrado tremendo y fascinante, el Dios de la religión, la praxis 
y la historia que se des-vela libre y gratuitamente y se re-vela ética y absolutamente. (pp. 15-16)

Scannone (2005), por su parte, comprende la filosofía como una fenomenología que se prolonga en hermenéutica, y es asumida en categorías analógicas de reflexión que,

no "en abstracto" y como "en el aire", sino a partir de la propia religión ( $\mathrm{y}$, añado, o irreligión), a través de un "transfert analogizante", que supone en el lector "una asunción en imaginación y en simpatía, compatible con la suspensión del compromiso de fe" [...] La propia (ir) religión proporciona así el correspondiente lugar hermenéutico de la reflexión filosófica. [...], se trata entonces de una universalidad situada, que yo interpreto como analógica y abierta en imaginación y en simpatía a las otras situaciones y opciones religiosas. (p. 33)

De esta manera, la filosofía es hermenéutica que experiencia su lugar en la teología católica latinoamericana desde la mirada de Scannone. El pobre es el oprimido, el excluido, y la opción por los pobres es universalmente humana y digna. Es una opción por lo humano íntegra (Scannone, 2007). El lugar hermenéutico es la sabiduría popular, la sabiduría del pobre en tanto es mediación entre la cultura, la religiosidad, los símbolos, las narrativas populares y el pensar filosófico (Rosolino, 2004). En este sentido, la tarea de la filosofía inculturada en América Latina es la de articular conceptualmente la lógica propia o racionalidad sapiencial de los pueblos latinoamericanos (Arenas, 2016). Es la inculturación la que proporciona una novedad de sentido en la filosofía de la religión en tanto es el pobre la realidad desde donde se interpreta lo inculturado latinoamericano. Es un nosotros ético e histórico como sujeto con su propia lógica y racionalidad sapiencial situada que busca transformar su realidad para lograr su liberación y hacer una reflexión de Dios a partir de las víctimas. Se trata de una apertura a la alteridad de los otros en tanto otros, en tanto sufrientes, como nuevo pensamiento para la recomprensión de la trascendencia de Dios. Las víctimas enseñan la sabiduría humana elemental a partir de las situaciones límite que han sufrido como sabiduría popular (Scannone, 1995). Por eso la filosofía de la liberación se mueve dentro de un nuevo paradigma (González, 1993), desde lo ético e histórico que sobrepasa lo contextuado y situado histórica y geopolíticamente.

La opción preferencial por los pobres es la opción latinoamericana del papa Francisco, la cual se evidencia en su exhortación Evangelii gaudium (n. 198), en la que "para la Iglesia la opción por los pobres es una categoría teológica antes que 
cultural, sociológica, política o filosófica", y por tanto, exige "una Iglesia pobre para los pobres. Ellos tienen mucho que enseñarnos. Además de participar en el sensus fidei, en sus propios dolores conocen a Cristo sufriente. Es necesario que nos dejemos evangelizar por ellos", quienes han de ser incluidos socialmente y con equidad.

\section{Conclusión}

El Documento de Medellín es el acontecimiento de la Iglesia católica en el que se visualiza esencialmente el futuro apostólico de la Iglesia en tierras latinoamericanas, y por tanto lo dialogado en este encuentro ha causado gran resonancia en Europa y otros continentes que ven el compromiso de una Iglesia fuerte a pesar de sus limitaciones. Por primera vez se dedica un documento a la juventud, lo que lleva a interpretar como un llamado de atención ante la importancia de la inclusión de los jóvenes en el campo eclesial y la sociedad, en que los jóvenes son detallados con lupa para poder aprovechar todo el potencial que estos tienen y que pueden aportar a la labor pastoral de la Iglesia, al encuentro y a la opción preferencial por los pobres.

La educación libradora en Latinoamérica tiene un gran interés por formar personas integrales, con capacidad de desenvolverse eficientemente en la sociedad, que desarrollen capacidades de dominio cultural y, sobre todo, con valores propios a partir de una formación sensible y humana. La filosofía de la liberación inicia en la realidad concreta de los pueblos latinoamericanos en su experiencia práxica histórico-social humana integral en tanto se acerca a las víctimas de los fenómenos de injusticia e inhumanidad. Es una filosofía de denuncia y de crítica a las alienantes condiciones que el colonialismo ha traído para el hombre latinoamericano. Es una filosofía que involucra desde el contexto latinoamericano a la sociedad en general para que responda al compromiso fundacional de la opción preferencial por los pobres, como lo hizo el Documento de Medellín.

\section{Referencias}

Adorno, T. W. (1989). Dialéctica negativa: la jerga de la autenticidad. Madrid, España: Akal.

Arenas Pacheco, G. E. (2016). Una aproximación al pensamiento inculturado en el itinerario intelectual de Juan Carlos Scannone. Pelícano, 2, 106-115. Recuperado de http://revistas.bibdigital.ucc.edu.ar/ojs/index.php/pelicano/article/view/1125 
Boasso, F. (1974). ¿Qué es la pastoral popular? Buenos Aires, Argentina: Patria Grande.

Consejo Episcopal Latinoamericano. (1979). Documento de Puebla. Recuperado de https://www.celam.org/documentos/Documento_Conclusivo_Puebla.pdf

Consejo Episcopal Latinoamericano. (1989). La Iglesia en la actual transformación de América Latina a la del Concilio. Bogotá, Colombia: Autor

Cullen, C. A. (1986). Fenomenología y sabiduría popular. En Autor, Reflexiones desde América. Vol. II: Ciencia y sabiduría: el problema de la filosofía en Latinoamérica (pp. 47-81). Rosario, Argentina: Fundación Ross.

Dussel, E. (1980). Filosofía de la liberación. Bogotá, Colombia: Universidad Santo Tomás.

Francisco. (2013). Evangelii gaudium. Recuperado de http://w2.vatican.va/content/ francesco/es/apost_exhortations/documents/papa-francesco_esortazioneap_20131124_evangelii-gaudium.html

Galindo, O. (1990). Algunas reflexiones sobre la filosofía inculturada. Trabajo presentado en la V Conferencia Nacional Científico Metodológica de la Enseñanza del Marxismo-Leninismo e Historia, La Habana, Cuba.

Girard, R. (1965). La violence et le sacré. París, Francia: Bruges.

González, A. (1993). El significado filosófico de la teología de la liberación. En J. Comblin, J. I. González Faus y J. Sobrino (Eds.), Cambio social y pensamiento cristiano en América Latina (pp. 145-160). Madrid, España: Trotta.

Kusch, R. (1976). Geocultura del hombre latinoamericano. Buenos Aires, Argentina: Colección de Estudios Latinoamericanos.

Kusch, R. (1978). Esbozo de una antropología filosófica americana. Buenos Aires, Argentina: Castañeda.

Kusch, R. (1986). América profunda. Buenos Aires, Argentina: Bonum.

Ley 115/1994, de 8 de febrero, por la cual se expide la ley general de educación.

Marion, J.-L. (2006). La comunión del nosotros y el tercero. Stromata, 62, 93-128.

Miró Quesada, F. (1974). Despertar y proyecto del filosofar latinoamericano. Ciudad de México, México: Fondo de Cultura Económica.

Pablo VI. (1965). Gaudium et spes. Recuperado de http://www.vatican.va/archive/ hist_councils/ii_vatican_council/documents/vat-ii_const_19651207_gaudium-etspes_sp.html

Pablo VI. (1967). Populorum progressio. Recuperado de http://w2.vatican.va/content/ paul-vi/es/encyclicals/documents/hf_p-vi_enc_26031967_populorum.html

Parada, H. (1975). Crónica de Medellín: segunda Conferencia General del Episcopado Latinoamericano, Bogotá, 24 de agosto, Medellín, agosto 26-septiembre 6, Colombia, 1968. Bogotá, Colombia: Indo-American Press Service.

Rosolino, G. (2004). La teología como historia: aportes recientes a la relación entre teología e historia. Córdoba, Argentina: Universidad Católica de Córdoba. 
Salazar Bondy, A. (1969). ¿Existe una filosofía de nuestra América? Ciudad de México, México: Siglo XXI.

Scannone, J. C. (1985). Ethos y sociedad en América Latina: perspectiva sistematicopastoral. Stromata, 1-2, 34-47.

Scannone, J. C. (1995). La religión en América Latina del tercer milenio: hacia una utopía realizable. Stromata, 51, 75-88.

Scannone, J. C. (2005). Religión y nuevo pensamiento: hacia una filosofía de la religión para nuestro tiempo desde América Latina. Barcelona, España: Anthropos.

Scannone, J. C. (2007). Las víctimas históricas como lugar de lo universal humano inculturado y de una filosofía intercultural. Stromata, 63, 201-206.

Solari, E. (2005). Sobre la filosofía de la religión en América Latina. Realidad: Revista de Ciencias Sociales y Humanidades, 103, 127-169. https://doi.org/10.5377/realidad. v0i103.4009

Tamayo-Acosta, J. J. (2004). Nuevo paradigma teológico. Madrid, España: Trotta.

Vidales, R. (1978). Desde la tradición de los pobres. Ciudad de México, México: Centro de Reflexión Teológica. 